\title{
PRODUÇÃO DE MUDAS PARA JARDIM NO ESTADO DE MINAS GERAIS ${ }^{1}$
}

\author{
Seedling production for garden in the state of Minas Gerais \\ Paulo Roberto Correa Landgraf ${ }^{2}$, Patrícia Duarte de Oliveira Paiva ${ }^{3}$
}

\begin{abstract}
RESUMO
A floricultura caracteriza-se pelo cultivo de plantas ornamentais, plantas de corte (flores e folhagens), plantas envasadas, floríferas ou não, até a produção de sementes, bulbos, palmeiras, mudas de árvores, arbustos e outras espécies para cultivo em jardim. Assim, objetivou-se realizar um estudo da produção de mudas para jardim no estado de Minas Gerais, aplicando-se um questionário aos produtores do estado de Minas Gerais, no período de 2003 a 2005. As visitas foram feitas in loco e os produtores foram identificados por meio de visitas nas áreas produtivas e os questionários foram respondidos por eles próprios. Analisando-se as respostas contidas nos questionários, identificou-se que a produção de mudas para jardim no estado de Minas Gerais é uma atividade realizada por 563 produtores, numa área plantada de aproximadamente 832,2425 ha.
\end{abstract}

Termos para indexação: Floricultura, mudas para jardim, produção de mudas para jardim, plantas ornamentais.

\begin{abstract}
Floriculture is characterized by the cultivation of ornamental and cut plants (flowers and foliages), potted plants, whether flowering or not, and even the production of seeds, bulbs, palm trees, seedlings of trees, shrubs and other species for cultivation in gardens. So, with the aim at accomplishing a study of seedling production for garden in the state of Minas Gerais, a questionnaire was applied to the growers of the state of Minas Gerais, over the period of 2003 to 2005 . The visits were paid in loco and the producers were identified by means of visits to the growing areas and the questionnaires were answered by them. By analyzing the answers contained in the questionnaires, it was identified that the production of garden seedlings in the state of Minas Gerais is a business carried out by 563 producers in a planted area of about 832.2425 ha.
\end{abstract}

Index terms: Floriculture, garden seedlings, production of garden seedlings, ornamental plants.

(Recebido em 4 de abril de 2006 e aprovado em 6 de julho de 2007)

\section{INTRODUÇÃO}

No Brasil, o interesse pela floricultura e plantas ornamentais evidenciou-se há alguns anos, quando as plantas começaram a ser apreciadas para a ornamentação, ocupando um lugar de destaque no cotidiano brasileiro.

A floricultura nacional, embora presente no cotidiano desde o final do século XIX, era pouco expressiva até meados da década de 50. As flores eram cultivadas principalmente nos jardins das residências e, quando exploradas profissionalmente, era uma atividade paralela a outras atividades. Ainda existia a imagem de que flores eram artigos supérfluos, gerando resistência a essa atividade econômica (ALMEIDA \& AKI, 1995).

Até alguns anos, o comércio era praticamente restrito ao estado de São Paulo, que é responsável por cerca de $70 \%$ da produção, mas tem se estendido a outros estados do País (AGRIANUAL, 2001).
As condições de produção do Brasil, dotado de diversidade de solo e clima, permitem o cultivo de grande número de espécies de comprovada qualidade e beleza.

No estado de Minas Gerais as principais regiões produtoras são: região de Barbacena; Sul de Minas, Grande $\mathrm{BH}$, entorno de Dona Eusébia, Teófilo Otoni e ainda Munhoz e Araxá. No entanto, não existem dados recentes dessa atividade no estado de Minas Gerais.

Dessa forma, há necessidade de se obterem informações referentes à produção de mudas para jardim, no estado de Minas Gerais, possibilitando um maior conhecimento do setor.

Atualmente, no Brasil, a venda e a distribuição de flores e plantas ornamentais é feita por meio de centrais de comercialização. Castro (1998) relata que existem centrais onde somente entram produtos dos próprios produtores, como é o caso do Veiling-Holambra e do Mercado Profissional da Floricultura e do Paisagismo (Mercaflor$\mathrm{SC}$ ); existem também aquelas onde entram produtos de

\footnotetext{
${ }^{1}$ Parte da tese de doutorado do primeiro autor, apresentada ao curso de pós-graduação em Fitotecnia, Universidade Federal de Lavras/UFLA - Caixa Postal 3037 - 37200-000 - Lavras, MG.

²Engenheiro Agrônomo, Professor - Universidade de Alfenas/UNIFENAS - 37130-000 - Alfenas, MG - paulo.landgraf@unifenas.br ${ }^{3}$ Engenheira Agrônoma, Professora - Departamento de Agricultura/DAG - Universidade Federal de Lavras/UFLA - Cx. P. 3037 - 37200-000 - Lavras, MG pdolivei@ufla.br
} 
fornecedores e atacadistas, como CEAGESP e a CEASACampinas e, ainda, aquelas onde somente se comercializam produtos de atacadistas, como a CEASA-Porto Alegre.

Para o ano de 2005, os principais segmentos comerciais da floricultura foram: mudas de plantas ornamentais, respondendo por $46,48 \%$ do total exportado, bulbos, tubérculos, rizomas e similares $(24,24 \%)$, flores frescas, folhagens, folhas e ramos secos de plantas e folhagens, folhas e ramos frescos cortados de plantas (JUNQUEIRA \& PEETZ, 2005).

Kampf et al. (1990) relatam que a floricultura nacional é uma atividade agrícola que requer pequenas áreas de cultivo, permitindo o aproveitamento de áreas marginais da agricultura tradicional. Assim, além de possibilitar um alto rendimento por área cultivada, pode constituir-se em uma fonte de renda alternativa para pequenos proprietários, localizados próximos a centros comerciais.

No Brasil, a profissionalização e o dinamismo comercial da floricultura são fenômenos relativamente recentes. No entanto, frente ao enorme mercado interno de consumo, a atividade já contabiliza números extremamente significativos. São mais de 4 mil produtores, cultivando uma área de cerca de 5,2 mil hectares anualmente. Embora com fortes tendências atuais de descentralização produtiva e comercial por várias regiões de todo o País, a atividade ainda é fortemente concentrada no estado de São Paulo e, particularmente, na região do município de Holambra. No total, estima-se a geração de 50 mil empregos (IBRAFLOR, 2005a).

A produção é desenvolvida em pequenas propriedades, cuja média nacional de área cultivada é de 3,5 hectares (JUNQUEIRA \& PEETZ, 2002).

Atualmente, no Brasil, estima-se como total a área cultivada de 5,2 mil hectares, abrangendo 304 municípios, divididos em 12 pólos de produção (IBRAFLOR, 2004).

Uma das principais características da produção de flores e plantas ornamentais é a de constituir-se em atividade típica de pequenos produtores. É bastante difícil precisar os números que envolvem a produção de flores e plantas ornamentais no Brasil, em virtude da inconsistência das informações disponíveis (CLARO, 1998).

Mudas de plantas ornamentais para jardim e paisagismo ocupam a maior área entre todos os segmentos considerados, somando cerca de 2,6 mil hectares. A maior parte consiste de arbustos e trepadeiras, com destaque para o cultivo de palmeiras Raphis excelsa (Thumberg) Henry ex. Rehder e Phoenix sp (GRAZIANO, 2002).

A produção brasileira de flores e plantas ornamentais, inicialmente concentrada no estado de São Paulo, tem se expandido para todo o país, com cultivo nos estados do Rio de Janeiro, Minas Gerais, Santa Catarina, Paraná, Rio Grande do Sul, Bahia, Alagoas, Pernambuco, Ceará e, também, na região Norte do País (IBRAFLOR, 2002).

Atualmente há importantes núcleos de produção de flores e plantas ornamentais no Brasil, formados principalmente em regiões onde existiam colônias de imigrantes japoneses e europeus, que trouxeram de seus países de origem, espécies e algumas técnicas de produção, como é o caso de São Paulo, Santa Catarina, Minas Gerais, Rio Grande do Sul, Espírito Santo e Pernambuco (IBRAFLOR, 2003).

De acordo com Silveira (1993), a produção de plantas ornamentais em Minas Gerais era localizada nas regiões de Barbacena, Juiz de Fora, São João Del Rei, Belo Horizonte, Congonhas, Mateus Leme, Sete Lagoas e Diamantina. Expandiu para Ituiutaba, Uberaba, Uberlândia, Viçosa, Patos de Minas, Paracatu, Teófilo Otoni, Governador Valadares, Montes Claros, Poços de Caldas, Alfenas, Itajubá, Lavras, Pouso Alegre, Munhoz, Andradas, Florestal, Joatuba, entre outras. A atividade era praticada por 342 produtores em 1987, demonstrando um razoável crescimento em relação à semelhante avaliação efetuada em 1979, quando se constatou a existência de 179 produtores, dispersos em uma área total de 120 ha. No ano de 1999, a atividade era praticada por 350 produtores, ocupando um total de 118 ha (IBRAFLOR, 2005b).

Entre as demais plantas ornamentais, destacam-se algumas mudas para jardim (azaléias, primaveras e dracenas, folhagens (aráceas), plantas envasadas (violeta africana e samambaia) e espécies arbóreas (bignoniáceas, melastomatáceas e leguminosas, principalmente). No total são comercialmente exploradas 120 diferentes plantas ornamentais (LANDGRAF \& PAIVA, 2005)

Na região central de Belo Horizonte existe o mercado de flores e plantas ornamentais. A iniciativa de criar esse Mercado Distrital foi da AMIFLOR, que teve o auxílio da prefeitura de Belo Horizonte.

Objetivou-se, no presente trabalho realizar um levantamento da produção de mudas para jardim, no estado de Minas Gerais.

\section{MATERIALE MÉTODOS}

O presente trabalho foi realizado no estado de Minas Gerais, que é constituído de 853 municípios e uma população de 17,5 milhões de habitantes, a segunda maior do Brasil, e é dividido em 10 macrorregiões de planejamento administrativo: Alto do Paranaíba, Central, Centro-Oeste, Jequitinhonha/Mucuri, Norte, Noroeste, Vale do Rio Doce, Sul, Triângulo e Zona da Mata, que se caracterizam por aspectos econômicos e sociais distintos, ocupando áreas territoriais com dimensões e recursos diversificados, conforme dados do IBGE (2005).

Este estudo foi realizado junto aos produtores de mudas para jardim. Como não foi encontrado nenhum 
cadastro ou registro desses produtores, a identificação deles foi feita de maneira exploratória, por meio de visitas às áreas produtivas. A produção de mudas para jardim foi diagnosticada por meio de um questionário, aplicado aos produtores das diferentes regiões do estado de Minas Gerais, no período de 2003 a 2005.

Para análise dos resultados utilizou-se estatística descritiva por meio de tabelas de freqüência, além de análise estratificada, conforme descreve Bussab \& Morettin (1987), de acordo com as diferentes macrorregiões de planejamento do estado de Minas Gerais.

\section{RESULTADOS E DISCUSSÃO}

Observa-se na Tabela 1, a porcentagem de produtores de mudas ornamentais cultivadas no estado de Minas Gerais. As maiores produções de mudas para jardim $(50,8 \%)$, mudas arbóreas (29,7\%), palmeiras (56,5\%), forrações (28,6\%), entre outras, concentram-se na Zona da Mata, onde destaca-se a cidade de Dona Eusébia. Nela, existem diversos produtores e as mudas são vendidas para todo o Brasil por meio de caminhões que, muitas vezes, param de cidade em cidade para a comercialização. As mudas são colocadas no chão, em pontos estratégicos onde aguardam pelos compradores. Em algumas cidades, observa-se que esses caminhões param próximos às feiras livres e, em outras, próximo ao trevo das cidades, onde fazem a comercialização. Na região do Jequitinhonha/Mucuri, que abriga as cidades de Teófilo Otoni e Lajinha, ocorre a produção em grande escala de mudas para jardim. As principais espécies produzidas são: mussaendra, hibisco, dracena, rosa, palmeiras, buganvília, pingo-de-ouro, ixória, antúrio e podocarpos. Essas mudas são comercializadas em saquinhos e também em torrão. É interessante que muitos produtores desses municípios não têm propriedades e produzem suas mudas na faixa de domínio do DER.

Na Tabela 2, são apresentados o número de produtores de mudas ornamentais produzidas no estado de Minas Gerais, segundo as regiões administrativas. Foram encontrados 563 produtores de mudas de plantas ornamentais em todo o estudo, destacando-se a região Zona da Mata, com 248 produtores.

Na Tabela 3, observa-se que a área de produção de mudas para jardim, é de 498,9270 ha. Em relação à produção de mudas de plantas ornamentais, observa-se que ela, atualmente, ocupa 832,2425 ha. Destaca-se a produção de mudas para jardim que ocupa $59,95 \%$ da área total cultivada com mudas. No Brasil, são 2,6 mil ha cultivados com essas espécies (GRAZIANO, 2002). Assim, Minas Gerais responde por $32 \%$. As produções de mudas arbóreas, mudas para jardim e mudas de palmeiras estão distribuídas em todas as regiões do Estado, mas concentradas principalmente na Zona da Mata e apresentando também uma boa produção na região Central.

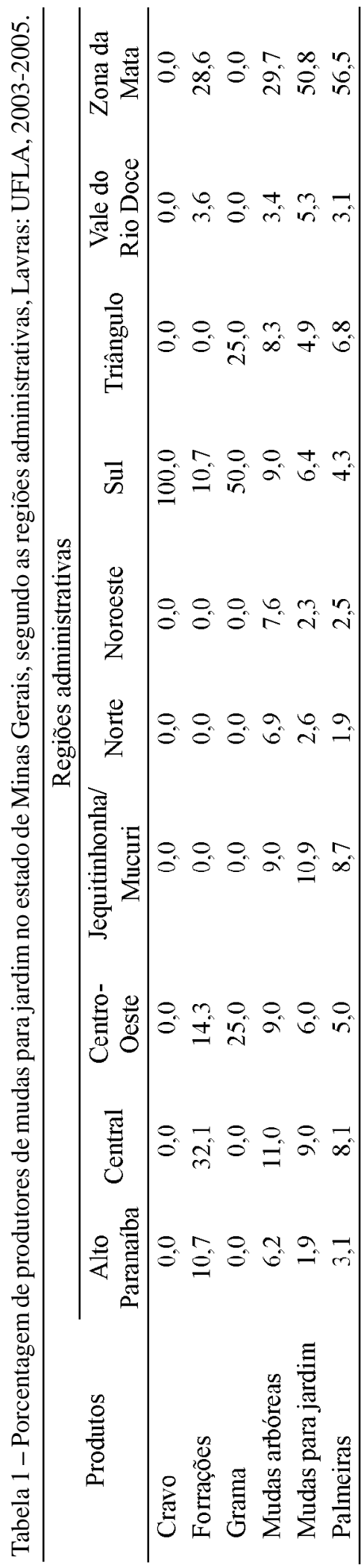

Ciênc. agrotec., Lavras, v. 33, n. 1, p. 127-131, jan./fev., 2009 

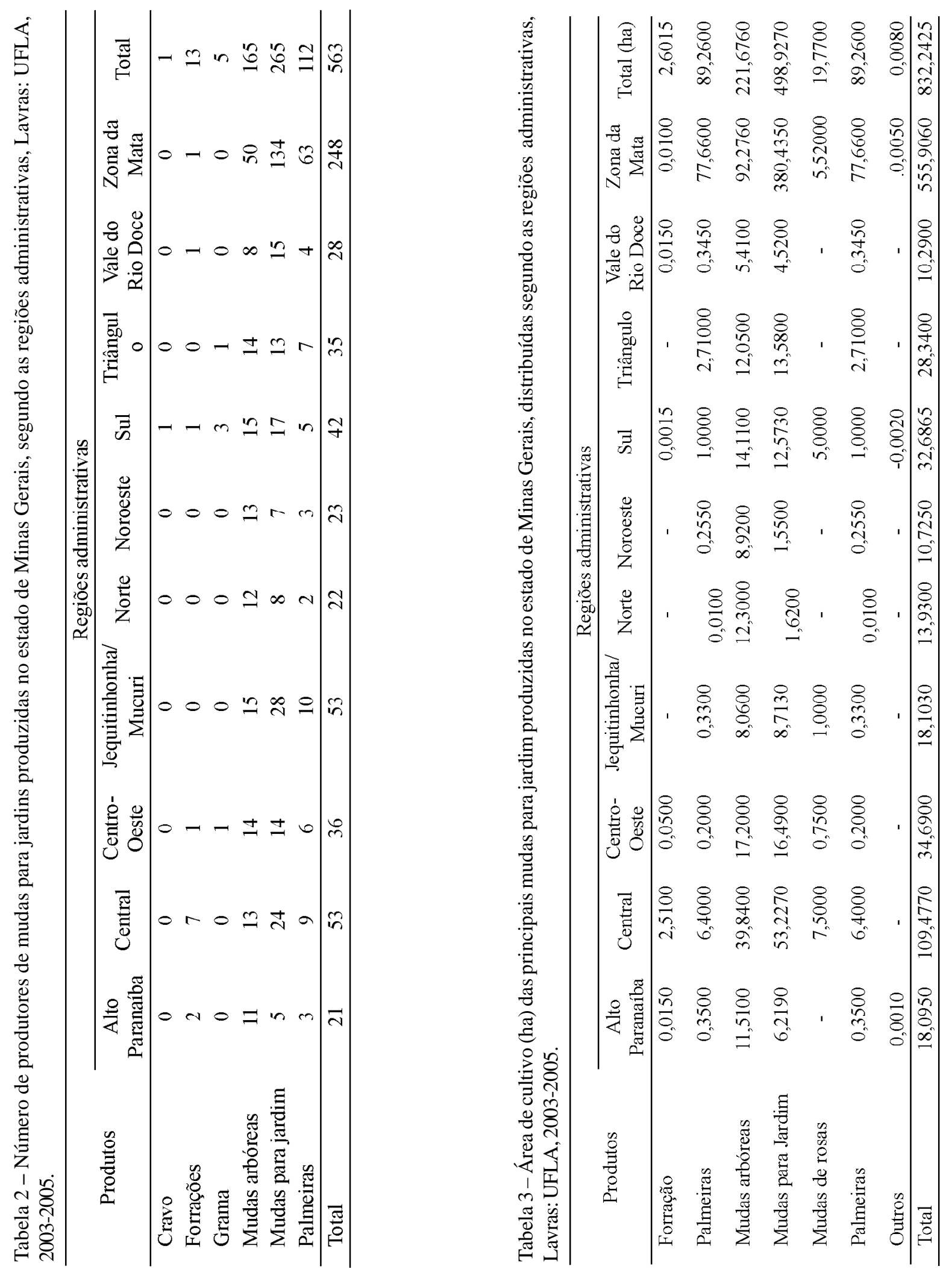

Ciênc. agrotec., Lavras, v. 33, n. 1, p. 127-131, jan./fev., 2009 


\section{CONCLUSÃO}

A partir dos resultados obtidos pelo estudo, podese concluir que a produção de mudas de plantas ornamentais no estado de Minas Gerais é uma atividade realizada por 563 produtores numa área plantada de 832,2425 ha; as principais espécies cultivadas são: mudas para jardim (498,92 ha), mudas arbóreas (221,67 ha), e mudas de palmeiras (89,26 ha); em porcentagem, tem-se a distribuição da área cultivada com plantas ornamentais em: 43,33\% para mudas de jardim, 19,23\% para mudas arbóreas, 7,51\% para mudas de palmeiras 27,73 para outras.

\section{REFERÊNCIAS BIBLIOGRÁFICAS}

AGRIANUAL. Anuário da agricultura brasileira. São Paulo: FNP Consultoria \& Comércio, 2001. 545 p.

ALMEIDA, F. R. F.; AKI, A. Y. Grande crescimento no mercado das flores. Agroanalysis, Rio de Janeiro, v. 15, n. 9, p. 8-11, set. 1995.

BUSSAB, W. O.; MORETTIN, P. A. Estatística básica: métodos quantitativos. 4. ed. São Paulo: Atual, 1987. 321 p.

CASTRO, C. E. F. Cadeia produtiva de flores e plantas ornamentais. Revista Brasileira de Horticultura Ornamental, Campinas, v. 4, n. 1/2, p. 1-46, 1998.

CLARO, D. P. Análise do complexo agroindustrial das flores do Brasil. 1998. 103 f. Dissertação (Mestrado) Universidade Federal de Lavras, Lavras, 1998.

GRAZIANO, J. da S. O que há de novo no rural brasileiro. Cadernos de Ciência e Tecnologia, Brasília, v. 19, n. 1, p. 37-67, jan./abr. 2002.

INSTITUTO BRASILEIRO DE FLORICULTURA. Levantamento Ibraflor 2001-02: banco de dados. Campinas, 2002.

INSTITUTO BRASILEIRO DE FLORICULTURA. Boletim informativo do Instituto Brasileiro de Floricultura. Campinas, 2003.
INSTITUTO BRASILEIRO DE FLORICULTURA. Programa brasileiro de exportações de flores e plantas ornamentais: resultados e ações para 2003/2004: irriga Ceará. Fortaleza: Secretaria de Agricultura e Pecuária do Estado do Ceará, 2004. CD-ROM.

INSTITUTO BRASILEIRO DE FLORICULTURA. Encontro brasileiro de dirigentes de mercado de flores e plantas ornamentais. Disponível em: <http:// ceasacampinas.com.br/ibra.htm>. Acesso em: 12 jul. $2005 \mathrm{a}$

INSTITUTO BRASILEIRO DE FLORICULTURA. Produção brasileira de flores: segundo IBRAFLOR. Disponível em: $<$ http://Www.uesb.br/flowery IBRAFLOR.pdf>. Acesso em: 3 jan. $2005 \mathrm{~b}$.

INSTITUTO BRASILEIRO DE GEOGRAFIA E ESTATÍSTICA. Dados populacionais municipais. Disponível em: 〈http://Www.ibge.gov.bri . Acesso em: 27 out. 2005.

JUNQUEIRA, A. H.; PEETS, M. S. Os pólos de produção de flores e plantas ornamentais do Brasil: uma análise do potencial exportador. Revista Brasileira de Horticultura ornamental, Campinas, v. 18 , n. $1 / 2$, p. 25 47, 2002.

JUNQUEIRA, A. H.; PEETS, M. S. Exportações brasileiras de flores e plantas ornamentais em 2005. [S.1.]: Hórtica Consultoria e Treinamento, 2005. 5 p.

KAMPF, E.; BAJAK, E.; JANK, M. S. O Brasil no mercado internacional de flores e plantas ornamentais. InformeGEP/DESR, [S.1.], v. 3, p. 3-11, 1990.

LANDGRAF, P. R. C.; PAIVA, P. D. de O. Produção e comercialização de flores em Minas Gerais. Informe Agropecuário, Belo Horizonte, v. 26, n. 227, p. 7-11, 2005.

SILVEIRA, R. B. de A. Floricultura no Brasil. Campinas: SBFPO, 1993. 